\title{
GEOPHYSICAL RESEARGH IN ALASKA
}

\section{O. Colbert*}

Qeveral fields of geophysical research depend for basic data upon observations of geodesy, which treats of the size and the shape of the earth. The following account describes the status of the geodetic network, of observations in the fields of gravity, geomagnetism, radio propagation, and seismology in Alaska, and suggests some problems of further study and research.

\section{Geodesy}

Observations over first order arcs of triangulation are adjusted by use of conditioning equations to provide a horizontal datum plane of reference. The adjustment of lines of precise level furnishes fixed elevations above the datum of sea level. The latter is determined by tidal observation at the sea coast over a period of years. Astronomical and gravity observations complete the data necessary to coordinate the network of meridians and parallels and points of precise elevations which are necessary for the delineation of surface characteristics and the determination of the geoid. In both the United States and Canada geodetic surveys are a government responsibility.

In Alaska the Coast and Geodetic Survey has made triangulation surveys along the entire coastal area. A continuous scheme of triangulation extends from the British Columbia-Alaska boundary through southeastern and southwestern Alaska, to the western extremity of the Aleutian Islands; by connection with the Alaska Peninsula, along the shoreline and on the islands of the Bering Sea to Bering Strait, the Arctic Ocean, and Point Barrow; thence along the northern shore of Alaska to the 141st meridian, where a junction is made with the survey of the International Boundary Commission. The latter triangulation completes the geodetic network around the periphery of Alaska. A connection has been made with the geodetic network of Canada in southeastern Alaska and on the Alaska Highway. In the interior, connecting loops exist over the areas adjacent to the Alaska Railroad, Richardson Highway, Glenn Highway, Tok Cutoff, Steese Highway, Yukon River from Tanana to St. Michael, Holitna River, Kuskokwim River, and east of Kotzebue Sound. Recently, arcs of triangulation have been extended from Fairbanks to Umiat, west to the Bering Sea shores and north to the arctic coast at the mouth of the Colville River; from Tanana to the Porcupine River, thence upstream to the

"Director, Washington Office, Arctic Institute of North America. 


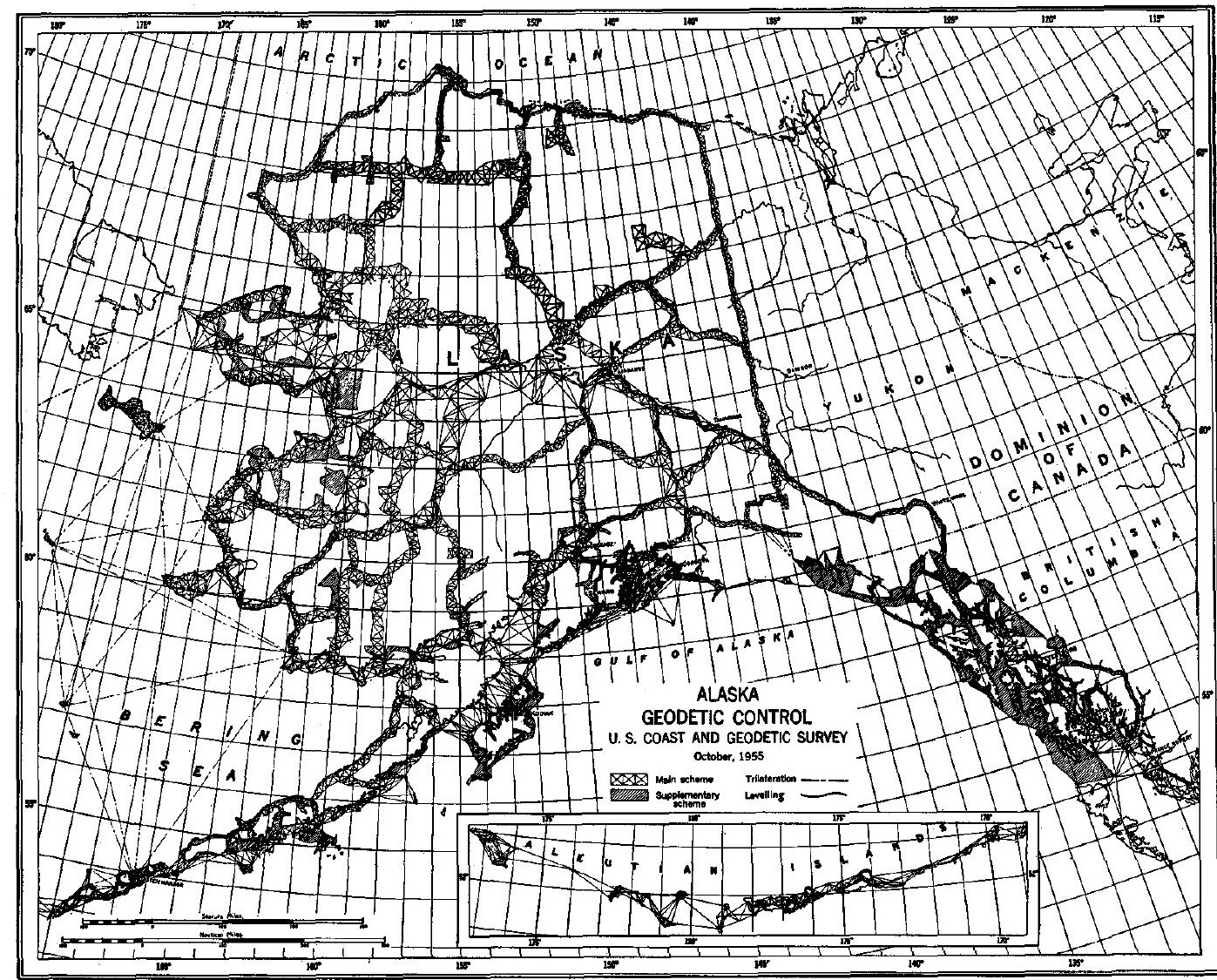

Fig. 1. Geodetic control in Alaska.

Alaska-Yukon Boundary. In addition to the main geodetic scheme, the Geological Survey and the Corps of Engineers have carried out triangulation projects for the preparation of topographical maps.

The elevations of established bench marks above mean sea level have been determined by lines of precise levels on the Alaska Highway from Whitehorse to Fairbanks, on the Richardson Highway from Fairbanks to Valdez and Chitina, on the Glenn Highway and the Tok Cutoff, and on the Steese Highway from Fairbanks to Circle, also from Haines over the Haines Cutoff. The long-range program contemplates levelling on the new highway from Paxson on the Richardson Highway to Cantwell on the Alaska Railroad; from Fairbanks to Livengood, and from Livengood to Eureka, thence to Manley Hotsprings, and downstream on the Yukon River to Kaltag, and thence to Unalakleet and St. Michael on the Bering Sea coast, where connections will be made to tidal bench marks.

The determination of the value of gravity at selected intervals for studies of the figure of the earth is one important phase of geodetic operations. In Alaska the immediate purpose of the gravimetric program of the Coast and 
Geodetic Survey is first to establish a system of gravity bases, and then a regional pattern of gravity stations determined with the gravimeter. The plan is to obtain sufficient gravity detail in one or more areas that gravimetric deflections of the vertical can be determined. These deflections, combined with astronomic-geodetic information referred to the North American 1927 datum, should produce valuable data for future determinations of the figure of the earth.

Another phase of this work is the basic coverage of gravity determinations for use in geophysical prospecting. Normally the value of gravity varies according to latitude and elevation. Any anomalous value indicates divergences which may probably be attributed to changes in the consistency of the earth's crust. Investigation of areas where anomalies occur may lead to the discovery of metallic ores or oil-bearing strata.

Gravity bases were recently determined by pendulum apparatus at Point Barrow, Umiat, Fairbanks, Anchorage, and Kodiak. Seventeen pendulum stations have been established between 1897 and 1952, and cover a latitude range from the 58th parallel to Point Barrow. Combined with the gravity pendulum project along the Alaska Highway the necessary basic control will be provided for more extensive gravimetric coverage. The ultimate goal is an area-breakdown of gravity determinations using gravimeters calibrated with reference to the basic gravity pendulum stations.

\section{Future work}

Considering the vast unmapped areas of arctic North America, it is essential that the programs initiated by the United States and Canada continue and, if possible, be accelerated in the interest of geophysical research. In Alaska, the long-range program calls for the extension of these surveys in the large area between the Yukon River and the Arctic Ocean, and for a gradual breakdown by means of closer spacing of arcs of triangulation to form a continuous geodetic network with all survey monuments interrelated. The program for shoran photogrammetry will extend knowledge of basic features of this area for topographical maps, for geological surveys, and for further detailed research.

Among the many problems in the Arctic of concern to the geodesist, the following may be listed:

1. Stability of survey marks. What is the best type of monument to set in various types of soil in the Arctic so as to ensure that the survey point will be stable in position both horizontally and vertically? There is already a limited amount of information available, but research with a definite program over a period of years is needed.

2. Vertical land movements. The relationship of mean sea level to surrounding land areas at the head of Lynn Canal has changed over a period of years. Are similar changes occurring at other places in the Arctic and Subarctic? Is the land rising, or the sea falling?

3. Horizontal land movements. In the regions of pronounced seismic activity in Alaska are movements occurring similar to those in California? 
Seismologists and geologists can perhaps tell the geodesist of regions susceptible to such movements so that a program of visual observations over a period of years may be initiated.

4. Heights of mountains. Elevations of Mount McKinley recently determined show an increase over earlier determinations. Is this increase due to greater deposition of snow on the peak, to greater precision in the measurements, or is it a real increase?

\section{Geomagnetism}

Geomagnetic data in Alaska have been gathered for many years by the Coast and Geodetic Survey. The work began with scattered observations by field parties in those areas most accessible to water routes, and by the establishment of the magnetic observatory at Sitka at the turn of the century. The present activities include the operation of magnetic observatories at Sitka, College, and Point Barrow; a network of repeat stations where observations are made at intervals of five years; broad regional surveys by airborne instruments; and steady accumulation of observations obtained by field parties primarily concerned with other phases of the Survey's activities.

Scientifically, the most important part of the magnetic work is that carried out at the laboratories, where highly trained observers maintain virtually unbroken recordings of changes in direction and intensity of the earth's magnetic field, and carry out frequent observations with absolute instruments. The repeat data are of importance in filling in the patterns of secular change; these stations are usually placed at sites convenient to air transport. The airborne surveys at high levels provide vital facts on the general patterns of distribution of the permanent field over vast interior and offshore areas, which cannot be adequately surveyed by older methods except at tremendous cost. Incidental magnetic data accruing from other survey field operations contribute to knowledge of local magnetic conditions in coastal waters where frequent occurrence of magnetic irregularity offers a potential menace to safety at sea.

One reason for special interest in Alaskan magnetic work lies in the fact that the Territory is nearly bisected by the auroral zone, and is ideally situated for a chain of magnetic observatories extending north and south of that zone. Valuable data on the pattern of magnetic storms and associated phenomena are being provided by the Sitka, College, and Point Barrow magnetic observatories.

\section{Future work}

It is clear that the relations of geomagnetic work to navigation, land surveying, radio propagation work, and geological investigations are all of such a nature as to stimulate and justify a sustained and expanded program in this vital field of science.

The following are some of the problems on which future work is needed:

1. The riddle of the elongated pattern of the permanent field northwest of the known magnetic pole. 
2. The behaviour of the auroral zone, especially during times of enhanced magnetic activity.

3. The development of procedures for forecasting the various kinds of solar and terrestrial activity that pertain to magnetism and to the use of radio facilities.

4. Increased understanding of daily magnetic variations, particularly with a view to eliminating the effects of various transient fluctuations from magnetic survey data, so that they may be of maximum benefit in geophysical and technological applications.

Some of these problems are currently being studied at the Geophysical Institute of the University of Alaska, and others at various establishments in the world centres of scientific study. There is need for closer spacing of repeat stations to delineate more accurately the location of isomagnetic lines in the northern area and to give basic data for comparison with airborne magnetic surveys and geophysical prospecting investigations.

\section{Ionosphere studies}

A study of radio wave propagation in the Arctic is part of an extensive research program of the Central Radio Propagation Laboratory of the National Bureau of Standards. The laboratory either operates, or has supplied equipment for the operation of eight arctic field stations to make regular soundings of the ionosphere at vertical incidence. Three of these are in Alaska (Point Barrow, College, and Anchorage), two are in Canada (Resolute Bay and Baker Lake), two are in Greenland (Godhavn and Narsarssuaq), and one is in Iceland (Rekjavik). The laboratory receives the data from these stations and is also provided with tabulations of hourly measurements made at each of nine other foreign arctic stations.

The observations at these stations give a measure of the electron density in the ionosphere. The variations of electron density with height, and the variations with time of day, season, and solar activity are of great theoretical interest and also of practical importance in studies aimed at improving radio communication in the Arctic. At College regular auroral observations are made, which include measurements of height and brightness. The radio data, when combined with these observations, not only add to the understanding of the relatively modern problems of radio wave propagation but should also aid in the solution of the ancient riddle of the Aurora Borealis.

The importance of these arctic studies by the National Bureau of Standards cannot be over-emphasized. Since radio gives the only possible means of communication over much of the vast area, any improvement in radio communication is extremely valuable. In addition, theoretical investigations of the arctic upper atmosphere may lead eventually to a better understanding of the physical world.

\section{Seismology}

Alaska is in general an area of only moderate seismological activity, but with important exceptions. The Aleutian Islands, the Alaska Peninsula, the 
southern half of central Alaska, and southeastern Alaska are all marked by major activity. The areas are part of the major tectonic formation known as the circum-Pacific earthquake belt, the most extensive of all such belts. It is characterized everywhere by young and growing mountains on land and by deep parallel trench formations off the coasts. In 1899 at Yakutat, near the eastern end of this belt, one of the greatest known earthquakes occurred, which shifted the shore rocks vertically by as much as 47 feet. In the trench southeast of Unimak Pass, in 1946, a submarine quake caused the sea bottom to rise initiating a seismic wave that destroyed the lighthouse at Scotch Cap with the loss of several lives, and then travelled across the deep Pacific Ocean to kill 173 people and destroy $\$ 25$ million worth of shore property at Hawaii.

Seismographs are operated at the Sitka and College geomagnetic observatories of the Coast and Geodetic Survey in Alaska. These stations and others outside Alaska provide the data needed to detect and locate the more important earthquakes originating in Alaska, to outline the various zones of seismic activity in the region, and to ascertain the degree of earthquake hazard in each. This information is of special value to engineers designing important structures, and to insurance companies needing statistical information on which to base earthquake insurance rates. Seismological techniques are also of value to geophysical prospectors.

\section{Future work}

Because the transmission and changing velocities of different types of seismic waves over various paths through the earth's interior can be calculated from seismographical data, significant deductions can be made regarding the structural and physical state of the interior of the earth. Additional seismological stations should be located in non-active areas in the north and along the arctic coast for this study. 